This paper is a postprint of a paper submitted to and accepted for publication in Transport Policy is subject to Transport Policy Copyright.

The full citation for this paper is:

Hounsell N.B., Shrestha B.P. and Piao J. (2011). Enhancing Park and Ride with Access Control: A Case Study of Southampton. Transport Policy, Volume 18, Issue 1, Pages 194-203, ISSN 0967-070X (doi:10.1016/j.tranpol.2010.08.002) 


\title{
Enhancing Park and Ride with access control: A case study of Southampton
}

\author{
Nick Hounsell, Birendra Shrestha and Jinan Piao \\ Transportation Research Group \\ School of Civil Engineering and the Environment \\ University of Southampton \\ Southampton, United Kingdom \\ Email: N.B.Hounsell@soton.ac.uk \\ Tel: +44 (0) 2380593705; Fax +44(0)2380593152
}

\begin{abstract}
Implementing and promoting more sustainable forms of urban transport are key policies of Local Authorities throughout the UK. Park and Ride (P\&R) is one such system implemented widely in the UK, especially in historic towns and cities with limited road and parking space in the centre. Some cities (e.g. Rome and London) have also implemented forms of 'access control' to reduce congestion and/or pollution in central areas. This paper describes a feasibility analysis of a unique application studied for potential implementation in Southampton - the integration of P\&R with access control on a key corridor in Eastern Southampton where traffic demand is likely to increase significantly in the coming years because of new housing developments. The system concept is a P\&R facility with express buses to the City centre, keeping the corridor free-flowing for these buses (and other traffic) by using a combination of bus lanes and access control.

Following an outline of the policy context and system design, this paper then describes the corridor and network modelling undertaken to predict the impacts of the scheme and alternatives of it. This has been based mainly on the CONTRAM dynamic traffic assignment model which covers the whole of Southampton and its surrounding motorway network. The assessment of the benefits of the various options in this scheme showed that the combination of P\&R with signalised access control was the best option to improve the movement of people on the corridor. The paper concludes with a discussion of potential issues for implementation, including the need for complimentary measures and a consistent policy framework.
\end{abstract}

\section{Key words:}

Park and Ride, Access control, Network modelling, Traffic management, Demand management

\section{Background}

Local Authorities in the UK are all seeking to implement and promote more sustainable forms of urban transport than currently exist, consistent with Central Government guidance (e.g. DfT, 2007). Park and Ride (P\&R) is one such system implemented widely in the UK, especially in historic towns and cities with limited road and parking space in the centre. Examples of such cities include Cambridge, York (Parkhurst, 2000) and Winchester (Wall and McDonald, 2007). In addition to such measures, some cities are controlling access to certain vehicle types in the central area. For example, in Rome (CIVITAS, 2008a), the numbers of high-polluting vehicles in the Limited Traffic Zone 
(LTZ) are restricted to encourage modal shift towards sustainable modes (such as ecobus and walking). In Cork (CIVITAS, 2008b), lane capacity is reduced on the cities' main arterial route and traffic is diverted away from the city centre and into P\&R facilities. London's Low Emission Zone (LEZ) is another example which aims to deter the most polluting vehicles from driving in the area to improve air quality (TfL, 2008).

In this context, research has been carried out to explore new approaches to road space utilisation in urban areas within the FUTURES project (www.sue-futures.org). FUTURES was a recent collaborative research project concerned with future transport technologies in urban areas, funded by the Engineering and Physical Sciences Research Council (EPSRC) under their Sustainable Urban Environment (SUE) Programme. One of the approaches studied within this project was an innovative combined access control and P\&R scheme in Southampton to maintain manageable traffic flow to the city centre and help the free movement of P\&R buses. The study focuses on one site in Southampton identified by Southampton City Council for future development in their 2nd Local Transport Plan (LTP) 2006-11 (SCC, 2006). The combined access control and P\&R scheme is consistent with the key strategic approach of the LTP called 'Reduce Manage - Invest'. This is an incremental three-stage approach which defines measures reducing travel demand ('Reduce') and better management of the existing network ('Manage') as the first and second stages to be considered before providing new infrastructure ('Invest').

The innovative aspect of the scheme studied in this research is that it implements two different traffic management/demand management measures to complement each other. Here, access control aims to reduce the demand on the route by delaying traffic wishing to enter it, according to available capacity, while the P\&R provides an efficient alternative mode to travel to the city centre.

The research described in this paper is mainly based on network modelling of the traffic on the corridor, including potential network effects in Southampton overall, using the CONTRAM dynamic traffic assignment model (Taylor, 2003). The paper assesses the benefits of access control combined with $P \& R$ to see the predicted effects of a range of alternative schemes, and concludes with a discussion of potential issues for implementation.

\section{Case study site}

Southampton is one of the major cities in the south of the UK and has a population of around 200,000 people. The city has a major port facility serving mainly passenger and Container shipping. With a regional international airport, two universities and substantial shopping centres, the city is one of the major economic centres in the region. Congestion in the city has been controlled largely through advanced traffic management and information schemes, operated from the ROMANSE centre, which is renowned as a leading facility of its type in Europe (Wren, 1996). However, most arterial routes into the city experience some congestion during peak periods, particularly the eastern corridor which is the focus of this research (see Figure 1).

The A3024 Bitterne corridor is the main eastern arterial route to and from the city centre (shown as a dotted line in Figure 1). Motorway traffic from the east of Southampton exits from the M27 junction 8 and joins other traffic from eastern dormitory areas to take the A3024 into the city centre. The route is around $6.2 \mathrm{~km}$ long between the Windhover roundabout and the city centre, with limited sections of with-flow bus lane. The road is mainly single carriageway inbound for $\sim 3 \mathrm{~km}$, then it changes to a 2 lane dual carriageway for most of the rest of the route. The exception is where the road narrows to single lane only at two railway over-bridges, which causes a bottleneck for inbound traffic 
in morning peak periods. The route has a high density of traffic signal installations, with a total of 22 signal controlled facilities (junctions and pedestrian crossings) along the 6.2 $\mathrm{km}$ route.

In the 1970s', a gating and demand management system was implemented on this corridor to improve bus journey times - widely known as the Bitterne scheme (DfT, 2000). This was an integrated traffic management scheme, involving gating, bus lanes, bus-only entry points (side-roads) and other traffic restrictions. In this scheme, illustrated in Figure 2, a railway bridge is a bottleneck on a route into the City Centre. The aim of that scheme was to move queues away from the approach to a narrow railway bridge to locations where buses could be provided with special facilities to avoid the queues. Side roads joining the main roads were gated causing queues on the side roads, while buses were given separate access points onto the main road, avoiding the queues. In addition, the Bursledon Road (main road) was also gated near its entry (at the start of a bus lane). The scheme was reported to have reduced bus journey times by an average of $31 / 2$ minutes without increasing overall delay to other vehicles (delays to these vehicles increased on the gated links but reduced on the main road corridor). The original scheme was based on fixed time traffic signal plans and operated successfully like this until the 1990's.

The scheme is still operational, being controlled now by the SCOOT ${ }^{1}$ UTC system (Hunt et al, 1981). SCOOT succeeds in controlling congestion to 'reasonable' levels, although inbound journey times are often higher than desirable in morning peak periods. This can be seen from the journey time data in Figure 3, which shows a representative day's data as obtained from the City's Automatic Number Plate Recognition (ANPR) cameras at the two ends of the corridor. This shows pre-peak inbound journey times of $\sim 10$ minutes doubling to $\sim 20$ minutes at mid-peak, whilst outbound journey times remain steady throughout the peak period at $\sim 10$ minutes.

Without any remedial measures, traffic conditions are anticipated to deteriorate on this corridor following the planned development of some 6000 new dwellings near the eastern entry to the route. The traffic generated from this new housing development will put a considerable strain in the A3024 route to city centre. To address this problem, Southampton City Council had proposed investigation of a Bus And Toll (BAT) lane on the inbound route (SCC, 2006). The concept was to introduce a BAT lane throughout the route, to make better use of the reserved road space and provide revenue for funding the scheme and for related transport initiatives. However, a feasibility carried out by TRG (TRG, 2007) concluded that the implementation of a BAT lane would be unlikely to be feasible due to the density of junctions on the route, the major road/bridge widening works needed, toll collection issues and insufficient journey time savings (to attract enough toll payers to use the BAT lane).

\footnotetext{
${ }^{1}$ SCOOT (Split, Cycle and Offset Optimisation Technique) is a traffic adaptive Urban Traffic Control (UTC) system developed by the Transport Research Laboratory (TRL) UK. It coordinates the operation of all the traffic signals in an area to give good progression to vehicles through the network and responds continuously as traffic flow changes throughout the day, as measured by its network of traffic detectors. Information from the detectors is input to the SCOOT model, which models the progression of the traffic from the detector through the stopline. It takes due account of the state of the signals and any consequent queues. The data from the model is then used by SCOOT in three optimisers which are continuously adapting three key traffic control parameters the amount of green for each approach at each junction (Split), the time between adjacent signals (Offset) and the total time allowed for a complete sequence of signal operations at a signalled intersection (Cycle time). The operation of the optimisers provides the necessary combination of responsiveness to traffic fluctuations and stability to maintain coordination.
} 
This study (TRG 2007) also recommended access control combined with Park and Ride as an alternative. This alternative: a single entry point to the route, ideally at the parkand-ride site, would be the simplest arrangement and would make enforcement considerably easier. An access control combined with Park \& Ride facility would be expected to encourage people to use public transport in the place of car, resulting in the reduction in traffic and better utilisation of road space, with a higher proportion of high occupancy vehicles. Access control based on an environmental theme (e.g. providing privileged access to clean vehicles) could also be included as an option.

Another reason for preferring access control on this corridor is because of the difficulty and the cost involved in widening the sections of single carriageway along it. These single carriageway sections are the ones which are often congested in peak periods. As increasing capacity is not possible, it is necessary to reduce vehicular demand (to reduce congestion). This is currently achieved through fairly complex queue-relocation strategies (DfT, 2000) which are only partially successful. Using access control provides a further restraint on demand, which should be able to prevent nearly all congestion occurring on the corridor.

\section{The proposed Scheme}

The proposed access control and Park and Ride (P\&R) scheme is based on the site at the beginning of the corridor. The P\&R facility provides an alternative mode to drivers to travel to the city centre (i.e. express bus). The access control facility is there to control general traffic in such a way that they do not impede buses. The access control strategy adopted in this study provides priority access to the buses and other designated priority groups (e.g. clean vehicles) to gain a time advantage over other traffic when entering the route. Non-priority traffic wishing to enter this route is metered using a signal controlled entry queue within the park-and-ride site. Metering would seek to keep the corridor freeflowing, with similar but stronger metering than used in the existing Bitterne Scheme. The site map of the proposed access control and park-and-ride site is shown in the Figure 4. The site, which is also used as a temporary P\&R facility for special events (e.g. football and cricket matches) is just west of the Windhover roundabout near junction 8 of the M27.

Initial analyses indicated that the site has enough space for a P\&R facility for over 2000 cars, as well as space for the access control facility (for queuing vehicles waiting to access the A3024). At this initial stage, however, designs have been based on only 1000 parking spaces being needed. The access control aspect of the scheme is aimed to provide different levels of access to vehicles based on vehicle type. The main components of the integrated scheme are as shown in Figure 4. These include:

1. A P\&R facility for 1000 cars;

2. Unrestricted passage for the P\&R buses to the route $A 3024$;

3. Privileged access to certain groups of vehicles, such as buses, high-occupancy vehicles and/or environmentally-friendly vehicles; and

4. Signal control for other vehicles that do not have priority access and would have to wait longer to gain access to the corridor (Electronically monitored).

Concerning point 4 , it should be noted that, whilst non-priority vehicles will be delayed at the access point, their overall journey time to the City Centre may be similar to the current situation, because of the improved traffic flows and more efficient signal coordination this allows on the route itself. (This neutrality in journey time was achieved with the original 'Bitterne Scheme'). Also of note here is that stronger access control measures may also be required at some access points along the route, to discourage traffic re-assignment onto alternative, less suitable routes. This is discussed later in the paper. 
The level of take-up of the P\&R facility will be influenced by the P\&R charge, the journey time advantage it offers to passengers and other issues related to parking, convenience, etc. In simple terms, a driver is likely to change mode to $P \& R$ if he/she perceives benefits in using P\&R buses instead of driving to the city centre. Access control will be used at the site to give this differential journey time benefit to the buses by delaying other traffic. However, the delays for those not eligible for priority access may result in drivers rerouting to other adjacent routes. For example, traffic entering Southampton from the east could travel further round the M27 and exit at junction 7 rather than at junction 8 and take a different route to the city. The effect of the scheme on all the road users is a major factor in the success of a scheme. Hence, it is necessary to estimate how overall traffic will be affected on the route and alternative routes nearby as a result of the proposed facilities. This forms the main part of the remainder of this paper.

\section{Methodology}

The traffic impact of the scheme was carried out utilising the existing CONTRAM ${ }^{2}$ model of the Southampton road network. The impact was assessed for the year 2018 taking account of the committed housing development in the area. The following assumptions were made in this modelling:

- There are no major changes in public transport services in the region during the study period affecting traffic flow on the route.

- There are no other major developments in the region altering the traffic pattern on the study corridor.

- There is no other form of road user charging introduced in the region (including national road charging scheme) that alters travel patterns.

Future traffic growth and generated traffic from the new housing development will cause increased traffic demand on the route, which needs to be estimated. Future traffic demand was calculated using a stepwise process: present traffic; future traffic with yearon-year growth and future traffic with increased demand due to housing developments.

\subsection{Model calibration with present traffic demand}

The CONTRAM model of Southampton was first calibrated and validated in the ealy 1990's. It was therefore necessary to asses how well it reflected traffic performance in 2008, particularly on the A3024 corridor. This was undertaken by comparing the journey times from CONTRAM with equivalent averages obtained from the Automatic Number Plate Recognition (ANPR) installations between Windhover roundabout and Kingsway road junction, as given in Table 1.

The table shows that the journey times modelled in CONTRAM were higher than recorded in the field, particularly from $0800 \mathrm{hrs}$ until $0915 \mathrm{hrs}$. The likelihood is that there had been changes in both traffic demand and capacity in the intervening years. For a feasibility study in its early stages, as occurring here, validation would be achieved most easily by adjusting demand (via the Origin-Destination matrices). Were the scheme

\footnotetext{
${ }^{2}$ CONTRAM (CONtinuous TRaffic Assignment Model) is a dynamic traffic assignment model taking account of time-varying traffic in a road network. It has a wide range of modelling tools for representing a variety of situations from congested urban networks to inter-urban regions. It takes as input the network definition and time-varying demand for travel between a set of origin and destination zones, and outputs the resulting network flows, routes and travel times. It combines a form of microscopic simulation of traffic quanta, called 'packets' by analogy with communication networks, with a macroscopic time-dependent traffic model (Taylor, 2003). In normal operation, its iterative modelling process produces a User Equilibrium solution, with user optimum routes derived according to the specified objective function (e.g. minimum journey time).
} 
subsequently taken forward, it would then justify a more detailed calibration, such as junction-to-junction measurements of capacity). It is also noted that interest at this stage was in the relative effects of two scenarios rather than in producing the statistical best-fit to the existing situation.

The traffic demand in the CONTRAM model was adjusted to bring the resulting journey times closer to the field data. In this process, simulation runs were carried out with A3024 westbound OD traffic reduced between $5 \%$ and $10 \%$. The result showed that scenario S7 (traffic reduced by 9.5\%) gave the closest fit with the observed journey times. Figure 5 shows the comparison of this scenario with the field journey times and the journey times using the existing demand in CONTRAM. This O-D matrix was therefore taken forward to the next stage of the study.

\subsection{Increased traffic in the future}

The increase in traffic as a result of national/regional trends was estimated using the growth factor from Trip End Model Presentation Program - TEMPRO (DfT, 2008). The growth factors obtained from the program for Southampton for year 2018 were 1.158 (production) and 1.122 (attraction). This means a 16\% increase in production traffic (outbound - out of city centre) and $12.2 \%$ increase in attraction traffic (inbound - to the city centre) over the period. This inbound traffic forecast is inline with Southampton City Council's 2nd LTP (SCC, 2006) growth rate of $10 \%$ over 10 year. These two sources led to a traffic growth rate of $1 \%$ per year being used in this study.

\subsection{Increased traffic due to committed new housing}

The increase in traffic as a result of 6000 new dwellings in the Hedge End area was estimated using the trip generation factors for the development. The trip generation factors for this purpose were obtained from TRICS for housing development in Fareham (Grantham, 2008). Table 2 shows the number of trips generated from the new housing development using this process.

The trips generated from the new dwelling area had to be distributed to estimate the share of this traffic which pass by the proposed P\&R site on its way into Southampton. From traffic generation analyses it was estimated that $25 \%$ of the traffic generated from the housing development would travel to Southampton in the morning peak past the P\&R site. Hence, the increase in the inbound traffic as a result of the development would be $236 \mathrm{veh} / \mathrm{hr}$ (25\% of $945 \mathrm{veh} / \mathrm{hr}$ ). So, for the morning peak period (07:00-09:30), the traffic demand was increased by 590 vehicles ( $236 \mathrm{veh} / \mathrm{hr}$ for 2.5 hours) for the network. This traffic was attributed to the different time slices according to the traffic demand profile for the corridor.

\subsection{Park \& Ride and access control modelling}

The percentage of modal shift from cars to buses is the main parameter in modelling the effect of the P\&R scheme. This percentage of modal shift is site specific and could depend on various factors including: quality of P\&R buses, $P \& R$ charge, differential journey time in comparison to cars and availability of the parking space in the city centre. Hence, it is quite difficult to predict exactly how many car drivers would change mode to park and ride buses in this particular case. (This could be estimated using a Stated Preference (SP) survey, but this was felt not to be warranted at this early feasibility stage of the study. The methodology chosen for selecting the diversion percentage is explained in Section 5.

Access control was modelled in a way to deliberately delay general traffic as necessary to control the traffic flow on the route. This was mainly achieved by using traffic signals before the access to the A3024 (i.e. at the egress from the P\&R site). The timing of the 
traffic signal controlling general traffic was varied to see the delay imposed on access controlled traffic, the change in traffic flow on the route and the overall journey time as a result.

\section{Simulation results}

The simulation study using CONTRAM was carried out initially to assess the effects of the increase in traffic due to the year-on-year traffic growth and due to the new housing development in Hedge End area. Simulation results predicted a network journey time increase of $22 \%$ (from 20962 veh-hr to 25479 veh-hr) in the ten year period from the present level, due to 'normal' traffic growth. A further $2 \%$ increase was predicted due to the new housing. The effect of the increased traffic in terms of the journey time on the A3024 is shown in Figure 6.

Even though the network journey time increased by only 22\%, Figure 6 shows that the route journey time could double for the time period 08:15 and 09:00. This would severely disrupt the morning peak traffic on this route heading to the city centre and it highlights the need for a robust measure such as the access control and P\&R scheme being considered in this study. This future traffic scenario (predicted 2015) provides the base case against which the integrated access control and P\&R scheme was evaluated, as described in the next sections.

\subsection{Effect of modal shift with the Park \& Ride facility}

The first scheme scenario modelled was a P\&R facility on its own (i.e. without access control).This scenario was modelled using a range of hypothetical modal shifts $(10 \%$, $20 \%, 30 \%, 40 \%, 50 \%$ and $100 \%$ ) to: (i) estimate the overall effects; and (ii) to help select a suitable percentage for the field situation. In this scenario, $10 \%$ of traffic was assumed to be 'clean and HOV vehicles' which can get un-delayed access to the route. Figure 7 shows the simulated effect of the increase in mode shift on the route journey time. It is clear that increasing modal shift can make a significant reduction in the journey time on the route. It is evident from the figure that a mode shift of $40 \%$ or more could bring down the journey time to the present levels in Figure 6 . The overall change in the traffic flow through the route as a result of the various levels of mode shift is given Table 3 .

Table 3 shows that traffic flows upstream of the P\&R (i.e. the start of the route) increase with the increase in mode shift, even though the flow through the route reduces by its end. This is because many car drivers/passengers take P\&R buses to travel through the route. It is to be noted that there are still some vehicles private cars at the end of the route even when the mode shift was $100 \%$. This is because another main road and some side roads join the route along its length (before the route end). Clearly, such a high mode shift would not happen in reality, not the least because when a route is not congested due to the mode shift then drivers may be more prepared to drive rather than use the P\&R service (i.e. a new equilibrium occurs).

The P\&R concept was for there to be an express bus service capable of carrying P\&R passengers to the city 'immediately'. With a frequent bus service (e.g. one bus every five minutes), passengers from 1000 cars (with average occupancy of 1.45) could travel on the park and ride buses (12 buses $\times 50$ passengers $\times 2.5$ hours). For such a bus service, the modal shift cannot be more than $30 \%$ ( $3^{\text {rd }}$ row of Table 3$)$. This level of modal shift happens to be that found in a previous major study (Parkhurst, 1999) which reported, from studies of 16 cities, that $31 \%$ of $P \& R$ users $(50 \%$ of $62 \%$ who travelled to city centre by car before $\mathrm{P} \& \mathrm{R}$ was introduced) would drive to the city centre in the absence of park and ride. Hence a $30 \%$ modal shift from car to P\&R was assumed for further modelling. 


\subsection{Effect of P\&R and Access control}

In this scenario, access control was implemented to delay general traffic to control the traffic flow on the route to the extent necessary. The delay was imposed with the help of a queuing lane and a traffic signal before entering to the route. (A long queuing lane was modelled at this stage, even though a parallel series of shorter lanes might be used in reality.) Different signal timings were used to vary the delays and to see the corresponding effect on the traffic. The following basic parameters were used in the simulation of this scenario: $10 \%$ Clean and HOV vehicles (as an illustration); $30 \%$ modal shift to buses with P\&R facility; P\&R spaces for1000 vehicles; and a bus frequency of every 6 minutes. It is to be noted that the modelling has been based on the first year of operation and has assumed, at this stage, that there is no traffic generation/suppression. This is reasonable as journey time for cars on this route are not expected to change substantially (due to the delays at the access control point in addition to the route journey time) and therefore measurable traffic generation/suppression would not be expected. A series of signal plans were selected to explore the impacts under different 'severities' of access control (as imposed by the signal timings used). The different options modelled in this scenario were:

- Base case with future demand

- P\&R only

- $P \& R$ no Signal - P\&R facility plus vehicles queuing in a non-priority lane.

- P\&R Signal (20/10) - P\&R facility plus traffic signal with green/red split of 20/10 secs.

- P\&R Signal (10/10) - P\&R facility plus traffic signal with green/red split of 10/10 secs.

- P\&R Signal (10/20) - P\&R facility plus traffic signal with green/red split of 10/20 secs.

- P\&R Signal (10/50) - P\&R facility plus traffic signal with green/red split of 10/50 secs.

Changes in traffic flow on the A3024 when using these different P\&R and access control options are shown in Table 4. This shows that combined P\&R and access control noticeably changes the traffic flow through the route. The traffic flow taking this route (route start) increased noticeably with the introduction of the P\&R facility. This increase in traffic is attributed to the increased capacity as a result of the modal shift to P\&R buses. As expected, access control measures have reduced traffic flows through the route. The flows have reduced with stricter access control as a result of the increased delays at the access control point. Even then, the traffic flow in the case of "P\&R and Signal (20/10)" option is similar to the "Future base" option. The flow is lowest with the strictest access control using traffic signal $(10 / 50)$ scenario.

Changes in journey time along the route (not including delay at access control point) as a result of these access control options are shown in Table 5. This table shows that journey time through the route reduces considerably with the implementation of access control measures in addition to the P\&R facility. This reduction is particularly noticeable during the 08:30-09:15 period. Mode shift to buses using the P\&R facility alone made a significant reduction $(\sim 16 \%)$ in the journey time through the route. This reduction is due to the reduced flow on the route as a result of some car drivers shifting to P\&R buses. The strictest access control measures (signal (10/20) and signal (10/50)) gave the lowest journey time due to the lowest traffic flows (see Table 5). However, the journey time reduction was marginal when comparing amongst signal control options. With such a small improvement in the journey time, a stricter option such as signal (10/50) causing very low flows is not efficient. Apart from the changes in the flows through the route, the effects on the network in terms of the journey time and distance travelled due to these various access control options are shown in Table 6.

Table 6 shows that there is a noticeable reduction in network journey time (727 veh-hrs) as a result of the P\&R facility because of the substitution of many car trips by buses. Signalised access control measures have shown some increase in network journey time 
than the P\&R facility alone. This is due to the fact the some of the drivers using the route may choose a different route to avoid the delay imposed by the access control. However, the changes due to these other combinations of signalised access controls and P\&R facility are marginal in comparison to $P \& R$ facility alone. The network journey time from these combinations are still much lower than the base case situation. The table also shows a similar trend of results in terms of network distance travelled. With these results, it can be concluded that the introduction of P\&R and access control measures have a marginal benefit on the network overall; no scenarios show a disbenefit.

Following completion of the modelling, a further check was carried out on the realism of the $30 \%$ diversion assumption to P\&R. Using the journey times through the route, a mode split analysis was carried out using the parameters from the Ashford P\&R study (RPS, 2005). Here the mode split analysis was carried out purely in terms of the route journey time (including any delays to the car at the access control point) and the mode penalty obtained from the study. Table 7 shows that the mode share of park and ride buses varies from $25 \%$ (without access control) to $41 \%$ with strictest control modelled. Among these access control options, the "P\&R Signal (20/10)" option produced a $28 \%$ modal share of the buses, using this process. This further justifies the $30 \%$ used in this study as being of a reasonable order of magnitude.

\section{Economic analysis}

The impact of various $P \& R$ and access control options were analysed in Section 5 in terms of the flows and journey times. These results were then extended into an economic assessment, taking account of: Journey time savings; fuel consumption; non-fuel costs; and carbon emissions. The economic analysis shown in Table 8 is based on the traffic flows (Table 4) and journey times (Table 5) obtained from the CONTRAM modelling. As there is a marginal benefits on the network overall (Table 6), the economic analysis given below is for the route only.

The following observations can be made on Table 8:

- The P\&R facility gives a significant economic benefit due to the modal shift of cars to the buses

- The economic benefits from P\&R with access control measures are fluctuating (values going up and down even with the stricter control).

- Among these access control options, "P\&R Signal (20/10)" option gives the highest economic benefits (£1268/hour). The benefit from this option is $\sim 20 \%$ higher than that from the P\&R alone.

- The value of time savings contributes more than $86 \%$ of the total economic benefits and the rest is from savings in vehicle operating costs and carbon emissions.

- The economic benefits of $£ 1268$ per hour results in $£ 0.8$ million savings per year for the morning peak only.

- The proposed scheme fits somewhere between a traffic management scheme and a 'major projects scheme, so the 'project life' could be taken as up to 60 years for economic assessment purposes (DfT 2008b). For illustration, based on a 30 year project life, and the current discount rate of 3.5\%, the Present Value of Benefits (PVB) for the Scheme would be $\sim £ 15$ million - assuming that benefits remain constant over this period. The Present Value of Costs (PVC) would need to be estimated to obtain a Net Present Value (NPV = PVB-PVC). A costing exercise has not been undertaken at this stage. However, it is clear that costs of a P\&R facility would be far below the PVB estimate, so there should be a good Net Present Value. This suggests a good economic justification in taking this proposal forward to a more detailed design and costing exercise. 


\section{Discussion}

The economic analysis showed that the combination of park and ride facility along with the signalised access control "P\&R and Signal (20/10)" is the best option and is likely to be highly cost effective. However, the results can be considered from different perspectives:

- The P\&R facility alone gave a significant economic benefit and the access control made a moderate improvement in addition. Hence, it may be argued that implementing P\&R only could give sufficient benefits. However, it is to be stressed that the access control inducing some delays to cars is necessary to maintain traffic at a level that does not impede bus movement. An unimpeded bus journey time is necessary to make it attractive to car drivers so that the $30 \%$ modal shift has a chance of happening. Without an access control measure, the journey time improvement, as a result of modal shift, could be taken up by attracted traffic form other routes. Hence the P\&R facility needs to be implemented in conjunction to some form of access control.

- Even though the analysis is based on the assumption of $30 \%$ modal shift, when looking at the journey time saving figures, even a lower percentage $(10 \%)$ of modal shift seems to give enough benefit to justify for the implementation of the scheme. Furthermore, the effect of reduced modal shift is expected to be similar across the options (except for the base case) and hence does not change the chosen option.

- The network level assessment can be viewed as the overall picture of the impact of the options implemented in the corridor. However, CONTRAM has an element of uncertainty ${ }^{3}$ which makes small changes difficult to interpret. Hence, comparisons of small changes in network level results need to be made with caution.

In addition to these issues, $P \& R$ may not be successful if there are ample and affordable car parking spaces available in the city centre. In this situation, people may divert from the route but may still use their car to go to the city centre. Hence, car parking facilities in the city centre may need to be restricted or their cost increased to discourage people driving to the city. Implementing such a policy along with the combined access control and P\&R facility could reduce traffic flows into the city centre noticeably. Moreover, implementing similar schemes on other main corridors could bolster the effectiveness of the access control system. One such example is Oxford (http://www.oxford.gov.uk/transport/park-and-ride.cfm) where there are 5 Park and Ride facilities around the ring road adjacent to the main access corridors to the city.

In terms of modelling, this study assumed a fixed percentage of modal change from private cars to buses even though the levels of access control were different. In reality, the modal change depends on the benefits perceived by the drivers which could be highly influenced by the level of access control in place. However, such detailed calculation of mode shift requires a behavioural survey of drivers using the route which was not feasible within this preliminary study.

\section{Concluding comments}

The study has shown that the combination of $P \& R$ with signalised access control is a potentially good option to improve the movement of people and reduce congestion on the

\footnotetext{
${ }^{3}$ CONTRAM is designed to model the varying traffic demand and congestion that occurs during the day and will represent the peaks of congestion as well as off-peak conditions within a single model. As in the case of all microscopic model, CONTRAM also has a certain degree of variability related to the queuing process, time-dependent queuing, 'blocking-back' modelling and associated traffic assignment.
} 
A3024 in Southampton. It could be achieved primarily with investment and controls at the P\&R/access point, with very little infrastructure investment needed along the A3024.

The assessment carried out in this study was based on CONTRAM modelling of a conceptual scheme without going into the detailed operational aspects. This study has shown that the combined $P \& R$ and access control scheme could maintain traffic at a reasonable level and should produce significant economic and environmental benefits. The study has illustrated how traffic signal-based access control provides operational flexibility which gives the best economic benefits. This could also provide an opportunity to impose variable delays to the traffic depending on demand if necessary.

However, successful implementation of this scheme may need some controversial policy changes for Southampton, such as parking restrictions and increased parking costs in the city centre which makes driving to the city centres less attractive. Furthermore, the overall effectiveness of access control could be bolstered by the implementation of access control in all main corridors to the city. If the scheme described is to be taken forward to detailed design, then more detailed simulation modelling will need to be carried out to assess the effectiveness of the concept in terms of the geometric and operational considerations.

\section{Acknowledgements}

This is paper is based on a study carried out for the Sustainable Urban Environment (SUE) project 'FUTURES' (GR/S90881/01) funded by the Engineering and Physical Sciences Research Council (EPSRC) in which Southampton City Council is a stakeholder. The authors would like to thank EPSRC for sponsoring the project and Southampton city Council for their valuable advice and suggestions which made this research possible.

\section{References}

CiViTAS (2008a). Access Restrictions in Rome. Downloadable from http://www.civitasinitiative. $\mathrm{org} / \mathrm{measure}$ sheet. phtml?language $=$ en\&id $=38$

CiViTAS (2008b). Restricting Cars in Cork City Council. Downloadable from http://www.civitas-initiative.org/measure_sheet.phtml?language=en\&id=229

DfT (2000). SCOOT gating. Traffic Advisory Leaflet 7/00, Department for Transport December 2000

DfT (2007). Towards a Sustainable Transport System: Supporting Economic Growth in a Low Carbon World. Department for transport, October 2007.

DfT (2008a). TEMPRO - Trip End Model Presentation Program, Department for Transport. Downloadable from http://www.dft.gov.uk/pgr/economics/software/tempro/integratedtransporteconomics3169

DfT (2008b). WebTAG - Transport Analysis Website, Department for Transport. Downloadable from http://www.webtag.org.uk/sitepages/whatis.htm

Grantham M. (2008). If Achieved, What Effects Will The Government Housing Targets Have On The Transport Infrastructure of Hampshire? MSc Dissertation, University of Southampton

Hunt, P. B., Robertson D. I., Bretherton R. D., Winton R. I. (1981). SCOOT: A Traffic Responsive Method of Co-ordinating Signals. Transport and Road Research Laboratory, Laboratory Report LR 1014, Crowthorne, UK 
Parkhurst G. (2000). Influence of bus-based park and ride facilities on user's car traffic. Transport Policy, 7 (2), 159-172

Parkhurst G. (1999). Does bus-based park assist the integration of local transport? Parking news, no.3, 1999 April

ROMANSE (2008). ROMANSE Traffic and Travel Information for Southampton. http://southampton.romanse.org.uk/

RPS (2005). Ashford Park and Ride Study Final Report. Downloadable from http://www.ashford.gov.uk/pdf/ParkRideReport.pdf

SCC (2006). Local Transport Plan 2006-2011. Southampton City Council, Southampton, 2006

Taylor N.B. (2003). The CONTRAM Dynamic Traffic Assignment Model. Networks and Spatial Economics, 3: (2003) 297-322

TfL (2008). Low Emission Zone Impacts Monitoring - Baseline Report, Transport for London, July 2008

TRG (2007). Combined Bus and Toll Lane, Working Report of FUTURES PA5c, Transportation Research Group, December 2007

Wall G. and McDonald M. (2007). Improving bus service quality and information in Winchester. Transport Policy, 14(2), 165-179

Wren A. (1996). ROMANSE - Road Management System for Europe. Proceedings of 24th PTRC European Transport Forum, Seminar H, Vol. 407 


\section{Figures}

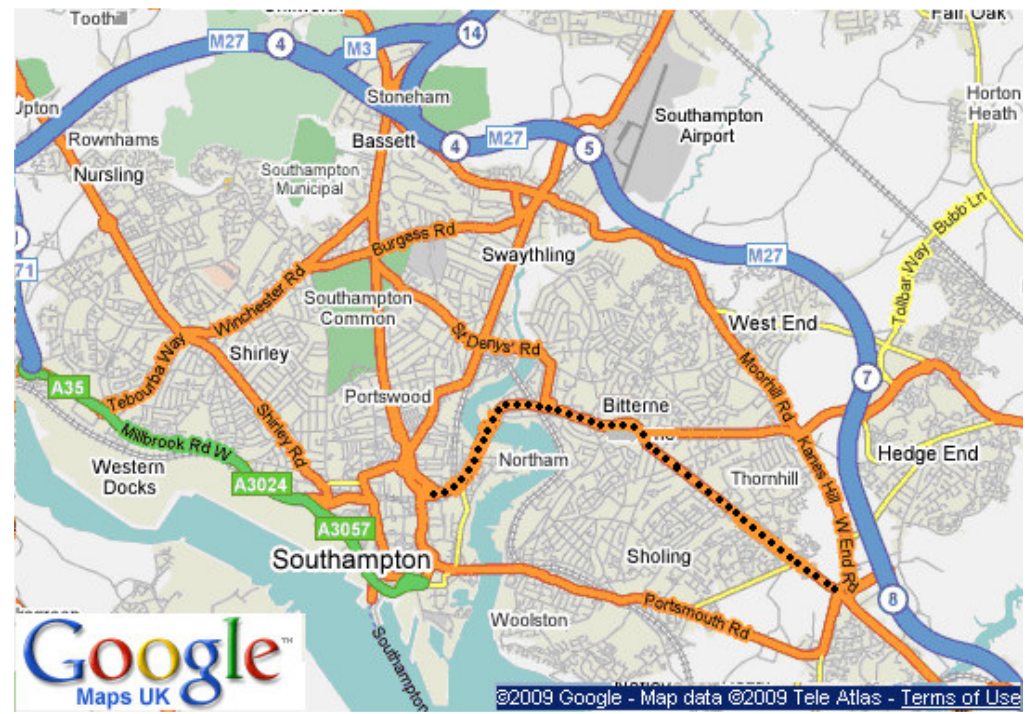

Figure 1: Map of Southampton showing A3024 route (Source: Google map)

THE BITTERNE ROAD

Main road gating point

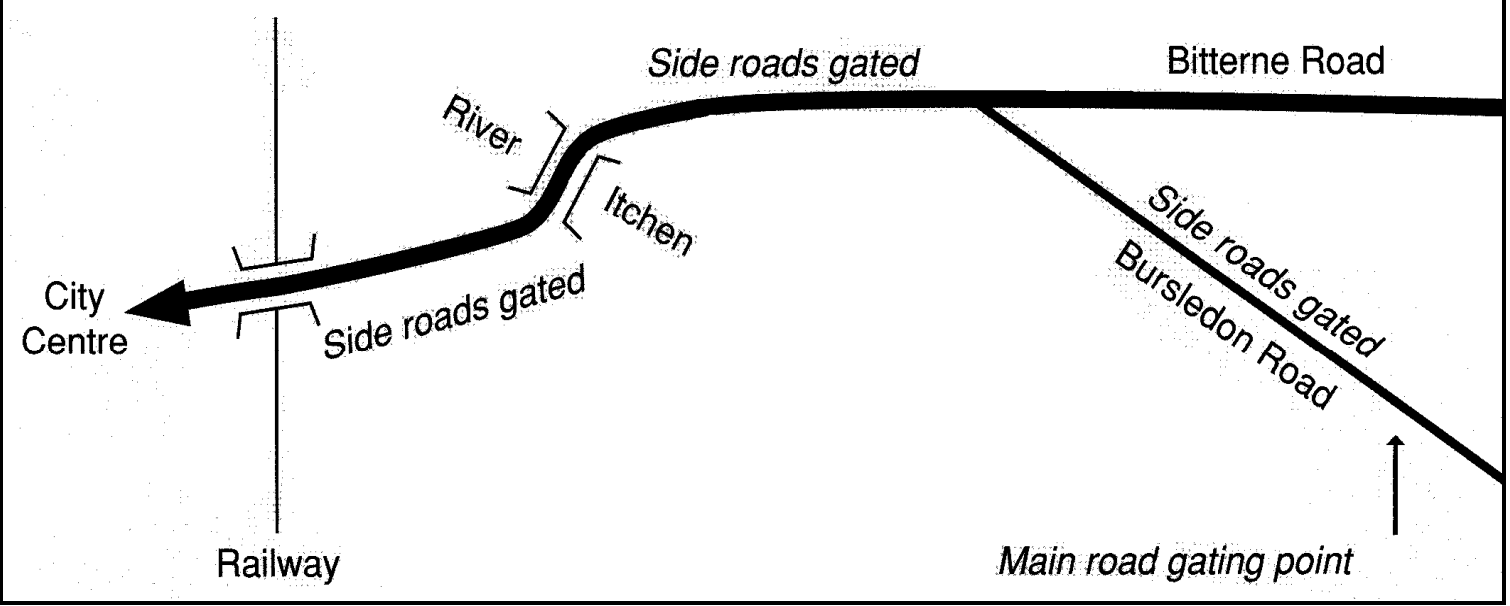

Figure 2: Diagram of the Bitterne scheme 


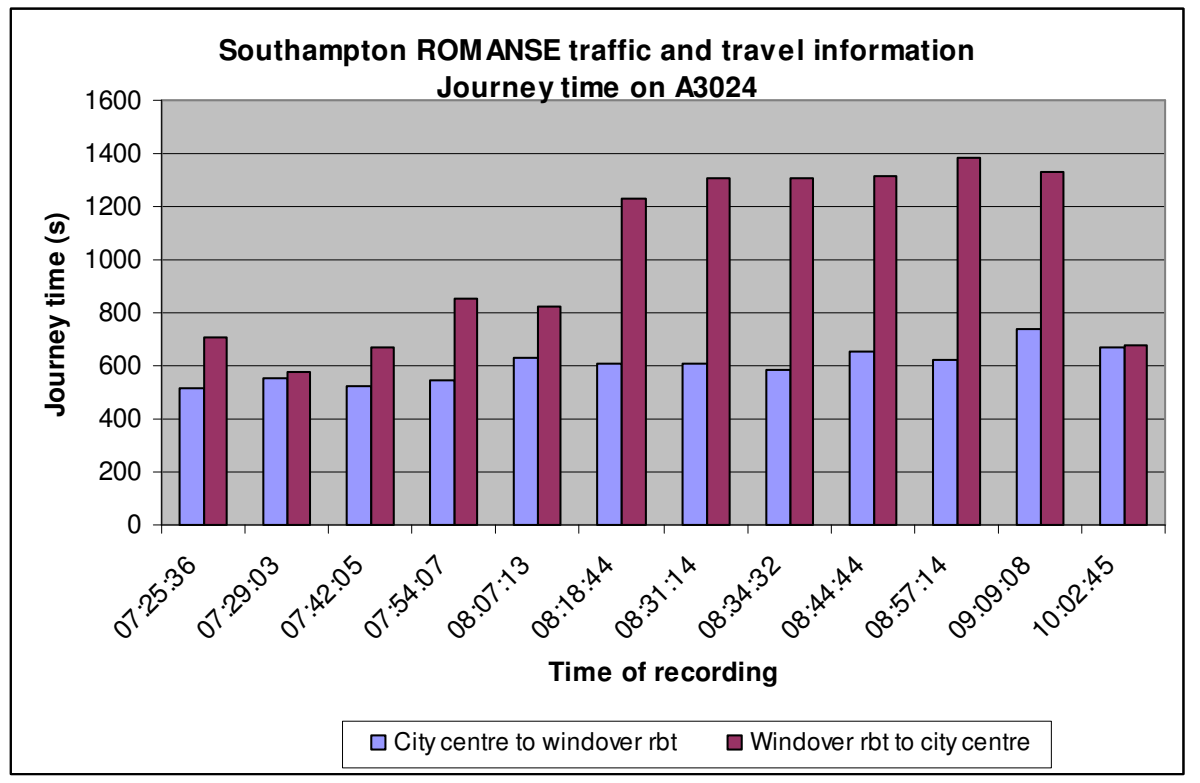

Figure 3: Two-way journey times on route A3024 in the morning peak period

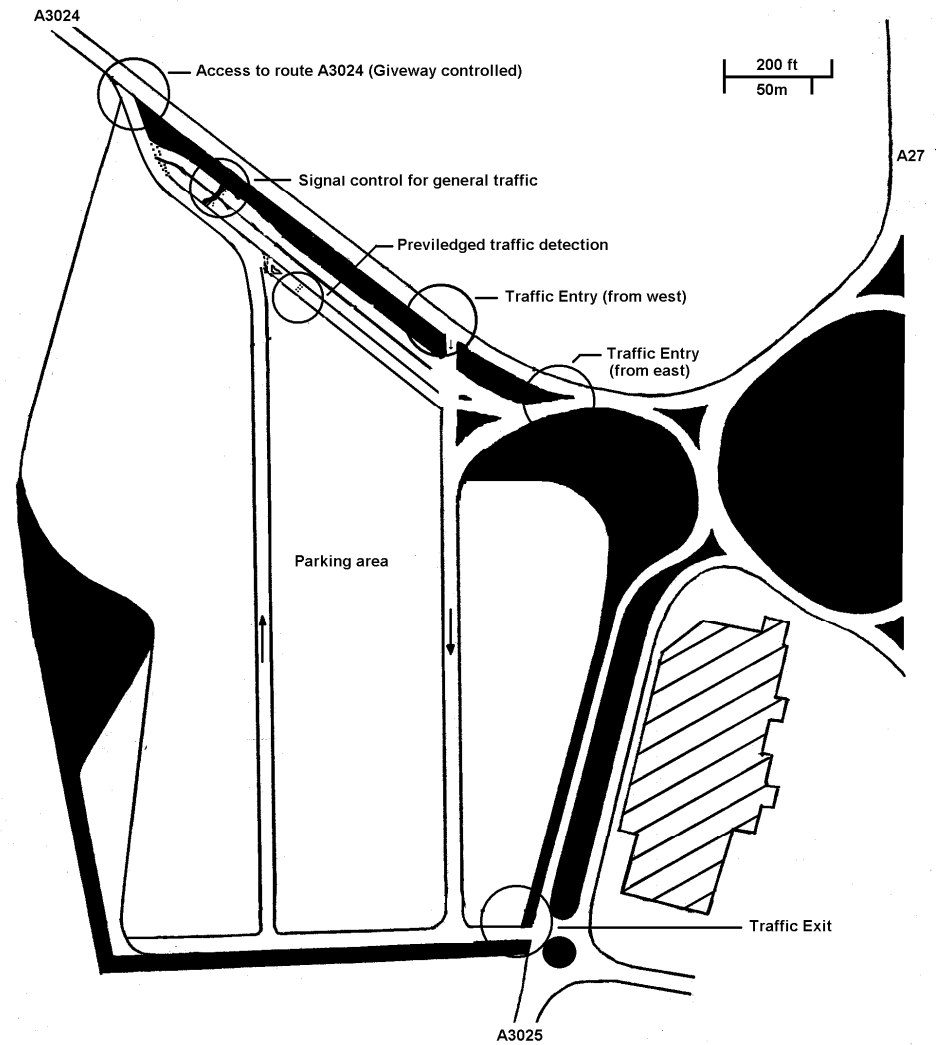

Figure 4: Proposed access control and park and ride site 


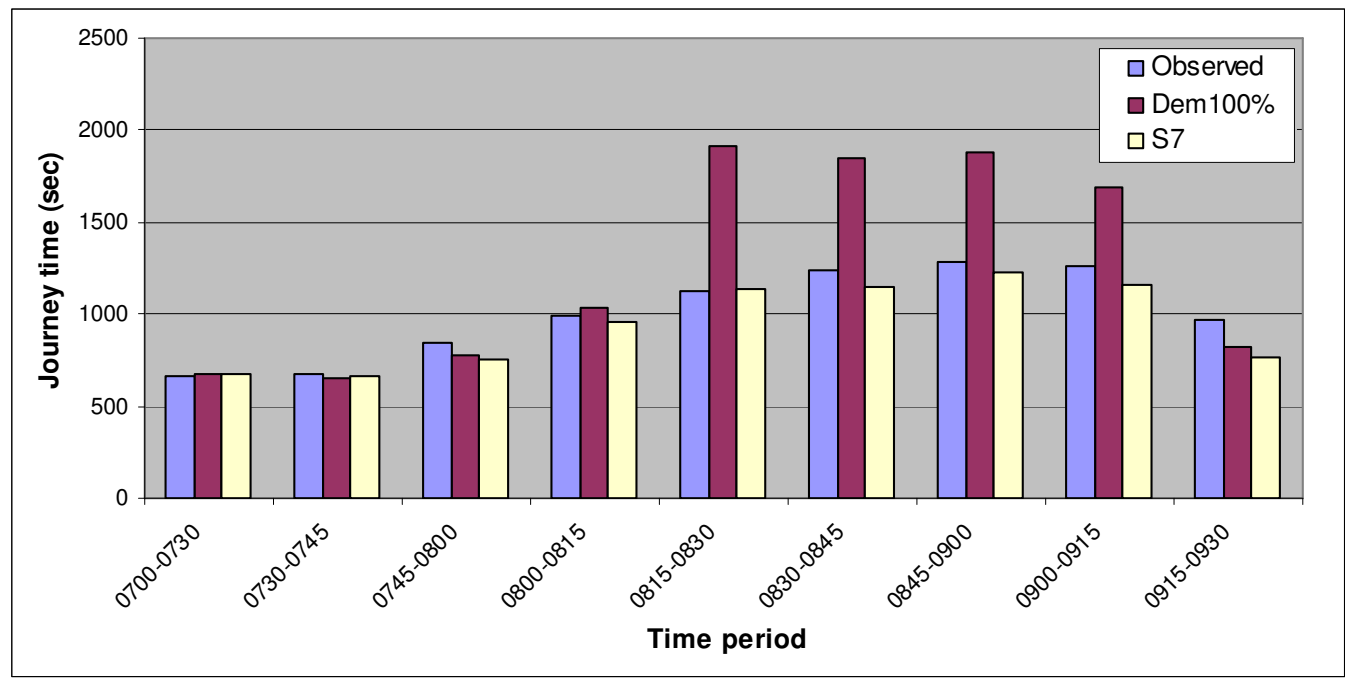

Figure 5: Comparison of journey times from different adjusted traffic flows

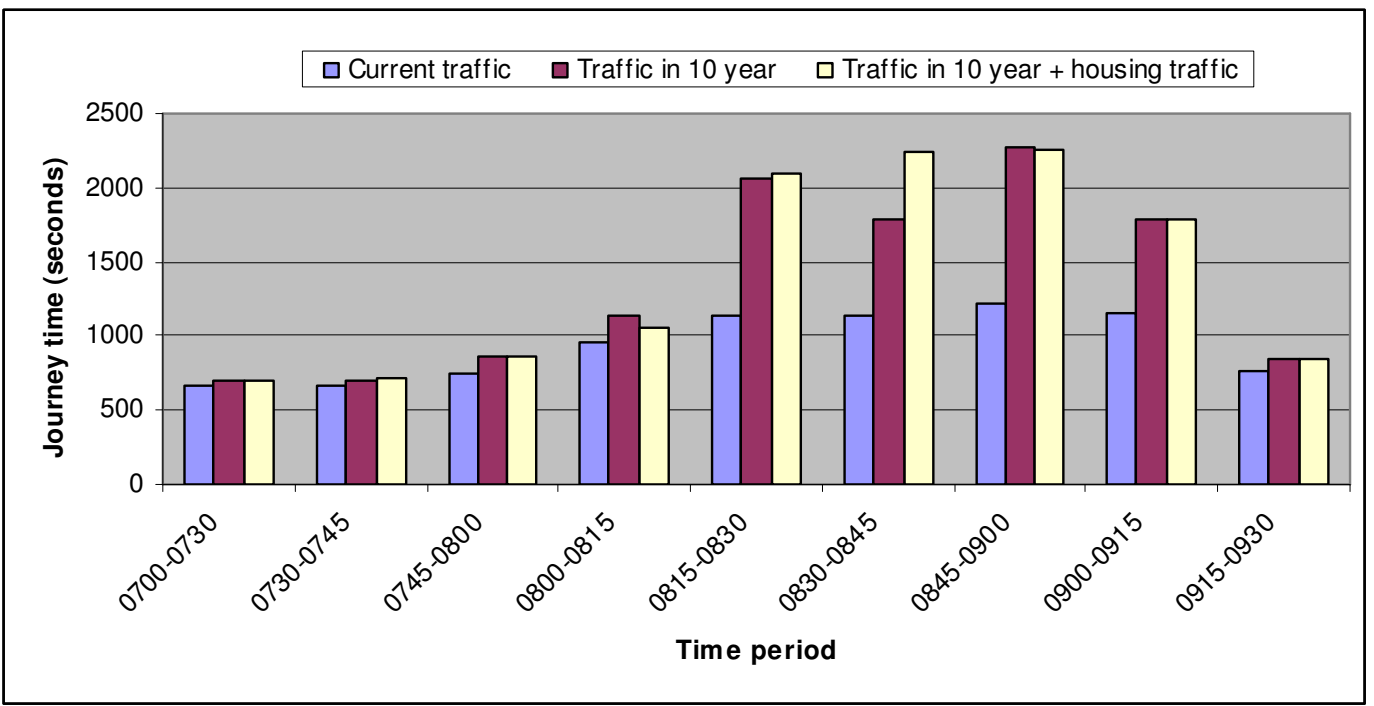

Figure 6: Effect of increased future traffic on route journey time

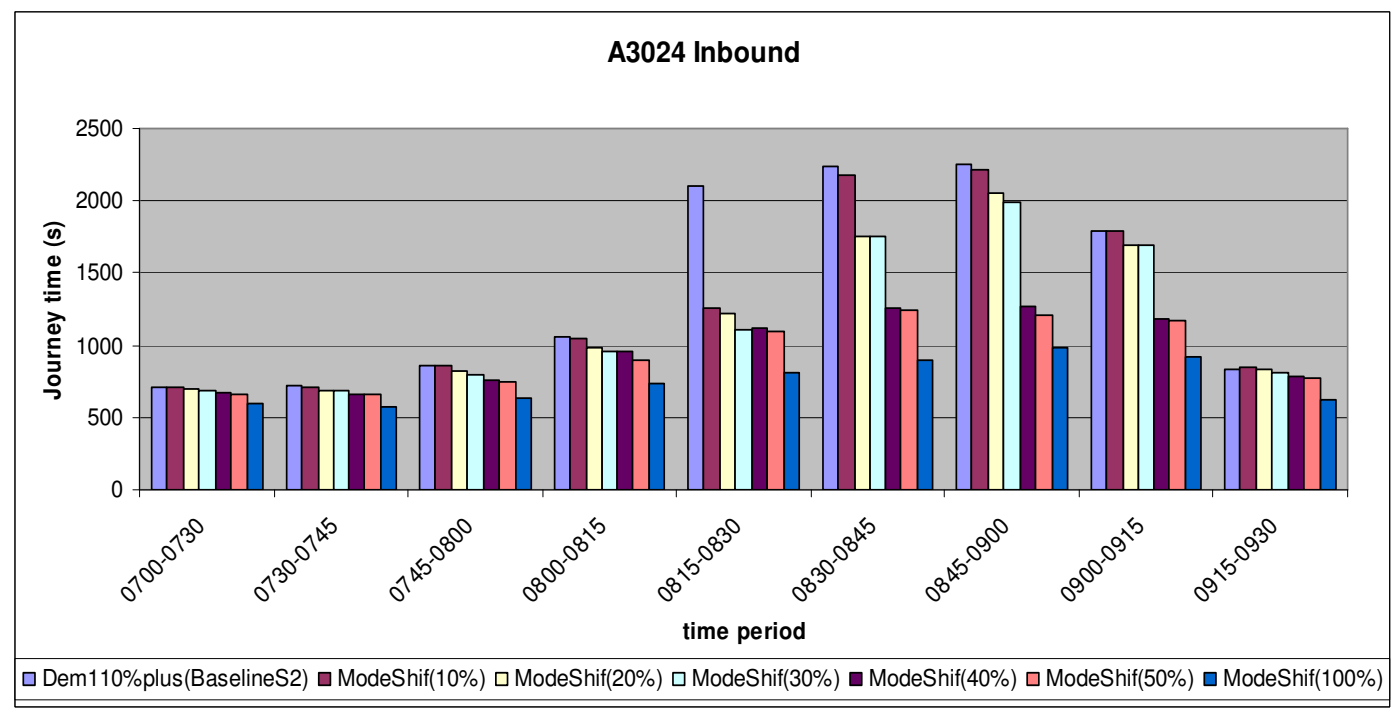

Figure 7: Journey time for different modal shift rates during morning peak 


\section{Tables}

Table 1: Journey time from CONTRAM and ANPR (in sec)

\begin{tabular}{ccc}
\hline Time period & ANPR & CONTRAM \\
\hline $0730-0745$ & 675 & 659 \\
\hline $0745-0800$ & 839 & 779 \\
\hline $0800-0815$ & 990 & 1033 \\
\hline $0815-0830$ & 1123 & 1912 \\
\hline $0830-0845$ & 1240 & 1852 \\
\hline $0845-0900$ & 1282 & 1883 \\
\hline $0900-0915$ & 1260 & 1684 \\
\hline $0915-0930$ & 966 & 821 \\
\hline
\end{tabular}

Table 2: Trip generation from the housing developments

\begin{tabular}{lrr}
\hline & AM peak & PM peak \\
\hline Dwellings & 6000 & 6000 \\
\hline Trip generation factor & 0.63 & 0.66 \\
\hline 2-way trips (peak hour) & 3780 & 3960 \\
\hline Inbound trips (2-hour) & 1890 & 1980 \\
\hline Inbound 1-hr trips & 945 & 990 \\
\hline
\end{tabular}

Table 3: Inbound traffic in A3024 for different modal shift rate (0700-0930)

\begin{tabular}{lccccccc}
\hline & Base case & MS10\% & MS20\% & MS30\% & MS40\% & MS50\% & MS100\% \\
\hline Route start (veh) & 2712 & 2852 & 3114 & 3348 & 3608 & 3877 & 4455 \\
\hline Using P\&R (veh) & 0 & 314 & 627 & 941 & 1255 & 1568 & 3137 \\
\hline Route end (veh) & 1192 & 1087 & 1130 & 1094 & 1000 & 968 & 295 \\
\hline
\end{tabular}

Table 4: Inbound traffic flow (veh) for different access controls (0700-0930)

\begin{tabular}{lrrrrrrrr}
\hline & $\begin{array}{l}\text { Future } \\
\text { base }\end{array}$ & P\&R & $\begin{array}{l}\text { P\&R No } \\
\text { Signal }\end{array}$ & $\begin{array}{l}\text { P\&R } \\
\text { Signal } \\
(20 / 10)\end{array}$ & $\begin{array}{l}\text { P\&R } \\
\text { Signal } \\
(10 / 10)\end{array}$ & $\begin{array}{l}\text { P\&R } \\
\text { Signal } \\
(10 / 20)\end{array}$ & $\begin{array}{l}\text { P\&R } \\
\text { Signal } \\
(10 / 50)\end{array}$ \\
\hline Route start & 2638 & 3385 & 2714 & 2617 & 2021 & 1781 & 1517 \\
\hline P\&R & 0 & 941 & 941 & 941 & 941 & 941 & 941 \\
\hline Clean/HOV & 185 & 233 & 274 & 289 & 317 & 334 & 335 \\
\hline Queuing & 0 & 0 & 1499 & 1387 & 638 & 506 & 241 \\
\hline Route end & 1194 & 1136 & 995 & 960 & 763 & 499 & 357 \\
\hline
\end{tabular}

Keys:

Route start - Number of vehicles detected at the beginning of the route

P\&R - Number of vehicles using P\&R facility

Clean/HOV - Number of clean and high occupancy vehicles using the route

Queuing - Number of vehicles queuing to get access into the route A3024

Route end - Number of vehicles detected at the end of the route

Table 5: Route Journey time (A3024 inbound) in seconds 


\begin{tabular}{lrrrrrrr}
\hline & $\begin{array}{l}\text { Future } \\
\text { base }\end{array}$ & P\&R & $\begin{array}{l}\text { P\&R } \\
\text { NoSignal }\end{array}$ & $\begin{array}{l}\text { P\&R } \\
\text { Signal } \\
(20 / 10)\end{array}$ & $\begin{array}{l}\text { P\&R } \\
\text { Signal } \\
(10 / 10)\end{array}$ & $\begin{array}{l}\text { P\&R } \\
\text { Signal } \\
(10 / 20)\end{array}$ & $\begin{array}{l}\text { P\&R } \\
\text { Signal } \\
(10 / 50)\end{array}$ \\
\hline $0700-0730$ & 705 & 688 & 649 & 643 & 620 & 609 & 598 \\
\hline $0730-0745$ & 722 & 671 & 630 & 622 & 604 & 591 & 589 \\
\hline $0745-0800$ & 888 & 784 & 763 & 753 & 690 & 698 & 682 \\
\hline $0800-0815$ & 1099 & 1031 & 999 & 932 & 888 & 815 & 864 \\
\hline $0815-0830$ & 2166 & 1144 & 1140 & 1093 & 1071 & 1090 & 1063 \\
\hline $0830-0845$ & 2120 & 1788 & 1780 & 1217 & 1782 & 1161 & 1169 \\
\hline $0845-0900$ & 2252 & 2037 & 2110 & 1310 & 1212 & 1234 & 1226 \\
\hline $0900-0915$ & 1778 & 1686 & 1636 & 1676 & 1229 & 1183 & 1221 \\
\hline $0915-0930$ & 861 & 793 & 795 & 800 & 783 & 792 & 778 \\
\hline Average & 1399 & 1180 & 1167 & 1005 & 987 & 908 & 910 \\
\hline
\end{tabular}

Table 6: A3024 inbound traffic / MS rates for using P\&R (0700-0930am)

\begin{tabular}{lccccccc}
\hline & $\begin{array}{c}\text { Future } \\
\text { base }\end{array}$ & P\&R & $\begin{array}{c}\text { P\&R } \\
\text { NoSignal }\end{array}$ & $\begin{array}{c}\text { P\&R } \\
\text { Signal } \\
(20 / 10)\end{array}$ & $\begin{array}{c}\text { P\&R } \\
\text { Signal } \\
(10 / 10)\end{array}$ & $\begin{array}{c}\text { P\&R } \\
\text { Signal } \\
(10 / 20)\end{array}$ & $\begin{array}{c}\text { P\&R } \\
\text { Signal } \\
(10 / 50)\end{array}$ \\
\hline Network JT (Veh-hr) & 25044.3 & 24316.8 & 24297.2 & 24343.1 & 24440.3 & 24380.2 & 24489.9 \\
\hline Network Dist (Veh-km) & 1027107 & 1014062 & 1014460 & 1014950 & 1015233 & 1016036 & 1015525 \\
\hline
\end{tabular}

Table 7: Modal share of Park and Ride buses and cars

\begin{tabular}{lccccccc}
\hline & $\begin{array}{c}\text { Future } \\
\text { base }\end{array}$ & P\&R & $\begin{array}{c}\text { P\&R No } \\
\text { Signal }\end{array}$ & $\begin{array}{c}\text { P\&R } \\
\text { Signal } \\
(20 / 10)\end{array}$ & $\begin{array}{c}\text { P\&R } \\
\text { Signal } \\
(10 / 10)\end{array}$ & $\begin{array}{c}\text { P\&R } \\
\text { Signal } \\
(10 / 20)\end{array}$ & $\begin{array}{c}\text { P\&R } \\
\text { Signal } \\
(10 / 50)\end{array}$ \\
\hline Bus & - & $25.4 \%$ & $27.3 \%$ & $28.4 \%$ & $34.7 \%$ & $37.2 \%$ & $40.6 \%$ \\
\hline Car & $-74.6 \%$ & $72.7 \%$ & $71.6 \%$ & $65.3 \%$ & $62.8 \%$ & $59.4 \%$ \\
\hline
\end{tabular}

Table 8: Economic analysis of different $P \& R$ and access control options ( $(/ h r)$

\begin{tabular}{lccccccc} 
& $\begin{array}{l}\text { Future } \\
\text { base }\end{array}$ & P\&R & $\begin{array}{c}\text { P\&R No } \\
\text { Signal }\end{array}$ & $\begin{array}{r}\text { P\&R } \\
\text { Signal } \\
(20 / 10)\end{array}$ & $\begin{array}{r}\text { P\&R } \\
\text { Signal } \\
(10 / 10)\end{array}$ & $\begin{array}{r}\text { P\&R } \\
\text { Signal } \\
(10 / 20)\end{array}$ & $\begin{array}{r}\text { P\&R } \\
\text { Signal } \\
(10 / 50)\end{array}$ \\
\hline Journey time savings & 0.00 & 903.05 & 666.81 & 1114.15 & 786.69 & 876.89 & 791.14 \\
\hline $\begin{array}{l}\text { VOC \& Carbon saving } \\
\text { (bus) }\end{array}$ & 0.00 & -47.81 & -47.52 & -43.92 & -43.51 & -41.72 & -41.77 \\
\hline $\begin{array}{l}\text { VOC \& Carbon saving } \\
\text { (P\&R car) }\end{array}$ & 0.00 & 174.05 & 174.05 & 174.05 & 174.05 & 174.05 & 174.05 \\
\hline $\begin{array}{l}\text { VOC \& Carbon saving } \\
\text { (non-queuing car) }\end{array}$ & 0.00 & 22.58 & 2.69 & 5.08 & 5.87 & 7.58 & 7.57 \\
\hline $\begin{array}{l}\text { VOC \& Carbon saving } \\
\text { (queuing car) }\end{array}$ & 0.00 & 0.00 & 11.06 & 18.66 & 5.27 & 3.91 & 1.03 \\
\hline Total savings & 0.00 & 1051.88 & 807.09 & 1268.02 & 928.38 & 1020.71 & 932.01 \\
\hline
\end{tabular}

